\title{
Effect of Ripening and Growing Conditions on the Content in Ascorbic Acid in Paprika Landraces
}

\author{
Ana M. RIBES-MOYA ${ }^{1}$, Ana FITA ${ }^{1}$, M. Dolores RAIGÓN² ${ }^{2}$ Adrián RODRÍGUEZ-BURRUEZO* \\ ${ }^{1}$ Instituto de Conservación y Mejora de la Agrodiversidad Valenciana. ${ }^{2}$ Departamento de Química. \\ Universitat Politècnica de València, Camino de Vera s/n, CP 46022, Valencia, Spain. \\ *)corresponding author, e-mail: adrodbur@doctor.upv.es
}

BulletinUASVM Horticulture 72(2) / 2015

Print ISSN 1843-5254, Electronic ISSN 1843-5394

DOI:10.15835/buasvmcn-hort:11646

\begin{abstract}
Spain is one of the most important centres of diversity for Capsicum annuum peppers and the highest producer and exporter in Europe, and a plethora of ecotypes can be found throughout the country. Such genetic heritage offers the opportunity of selecting materials adapted to organic cultivation. In addition, ascorbic acid (AA) is a bioactive compound of paramount importance and therefore studies on the effect of organic cultivation on AA levels can provide an added value to those genotypes selected for organic cultivation. In this work $C$. annuum landraces were submitted to a comparative study (organic vs. conventional cultivation). Fruits from each accession and growing condition were sampled at both unripe and fully ripe stages and AA levels were estimated by potentiometric titration. Genotype (G), ripening stage (RS), growing conditions (GC), and $G \times G C$ and $G \times R S$ interactions contributed significantly to the observed variation. In addition, ripening increased AA in all accessions. Furthermore, the average AA content was higher in the organic plot at both unripe and fully ripe stages. In this way, most organicproduced accessions showed similar or higher values than those observed in the conventional plot. Finally, a significant genotypexgrowing conditions interaction was found for fully ripe stage, suggesting that there are ample opportunities for selecting vitamin C-rich paprika landraces adapted to organic cultivation.
\end{abstract}

Keywords: Capsicum annuum, genetic diversity, landraces, antioxidants, organic agriculture.

\section{Introduction}

Spain is an important centre of diversity for peppers (Capsicum annuum) particularly bell peppers. A huge gene pool from America was introduced, grown, selected and adapted to specific agroclimatic conditions in Spain for generations since $16^{\text {th }}$ century. As a result, Spain is nowadays the highest producer and exporter of peppers in Europe (FAO, 2015) and most regions in Spain have their own ecotypes. Such heritage offers breeders the opportunity of selecting materials adapted to organic cultivation, particularly with high added value based on bioactive compounds, being ascorbic acid (AA) the most important antioxidant in peppers (Rodríguez-Burruezo and Nuez, 2006). However, studies aimed at the effect of organic cultivation on AA content are quite scarce. Moreover, the effect of ripening is also essential as they are sold at both stages: unripe and fully ripe. This work shows a preliminary study on the effect of growing conditions, ripening stage and their interaction on AA levels in a collection of $C$. annuum landraces.

\section{Materials and methods}

Six C. annuum landraces, mostly Spanish, were grown during spring-summer season in an experimental field of Bonrepòs i Mirambell, (Valencia, Spain), in two separate plots $(200 \mathrm{~m}$ distance): organic and conventional cultivation. Fruits of each accession and growing condition were sampled at both unripe and fully ripe stages, and AA levels were estimated by potentiometric titration by selective electrode, using a Titrino 702 automatic titrater and a $0.05 \mathrm{M}$ chloramine T solution as a standard. 
Tab. 1. (a) General and (b) ripening stage-specific ANOVA for the content of ascorbic acid (AA).

\begin{tabular}{lcc}
\hline \multirow{2}{*}{ Efect } & \multicolumn{2}{c}{$\mathbf{A A}$} \\
\cline { 2 - 3 } & $\mathbf{d f ^ { \mathbf { 1 } }} \mathbf{M}$ & $\mathbf{S}^{\mathbf{2}}$ \\
\hline Principals & \multicolumn{2}{c}{} \\
Genotype (G) 5 & \multicolumn{1}{c}{$8887,8^{* * *}$} \\
Growing conditions (GC) & 1 & $11968,9^{* * *}$ \\
Ripening stage (RS) & 1 & $141647,0^{* * *}$ \\
Interactions & & \\
G x GC & 5 & $4656,1^{* * *}$ \\
Gx RS & 5 & $2332,9^{* *}$ \\
GC x RS & 1 & $76,5^{\mathrm{NS}}$ \\
Residue & 59 & 672,3 \\
\hline
\end{tabular}

\begin{tabular}{|c|c|c|c|c|}
\hline \multirow{3}{*}{ Efect } & \multicolumn{2}{|c|}{ Unripe } & \multicolumn{2}{|c|}{ Fully ripe } \\
\hline & \multicolumn{2}{|c|}{$\mathbf{A A}$} & \multicolumn{2}{|r|}{$\mathbf{A A}$} \\
\hline & df $M$ & $\mathbf{S}$ & df & MS \\
\hline \multicolumn{5}{|l|}{ Principals } \\
\hline Genotype $(\mathrm{G})$ & 5 & $1296,7^{\mathrm{NS}} 5$ & & $9684 * * *$ \\
\hline Growing conditions (GC) & 1 & $5752,8 * * 1$ & & $6710,5^{* *}$ \\
\hline \multicolumn{5}{|l|}{ Interactions } \\
\hline $\mathrm{G} \times \mathrm{GC}$ & 5 & $1605,6^{\mathrm{NS}} 5$ & & $3686,6^{* *}$ \\
\hline Error & 30 & 676,5 & 24 & 674,8 \\
\hline
\end{tabular}

1 degree freedom; 2mean square. NS, ${ }^{*},{ }^{* *} \mathrm{y}^{* * *}$ indicate no significant and significant at $\mathrm{p}>0.05 \mathrm{and} \mathrm{p}<0.05,0.01$ and 0.001 , respectively, according to the statistical $\mathrm{F}$ ratio.

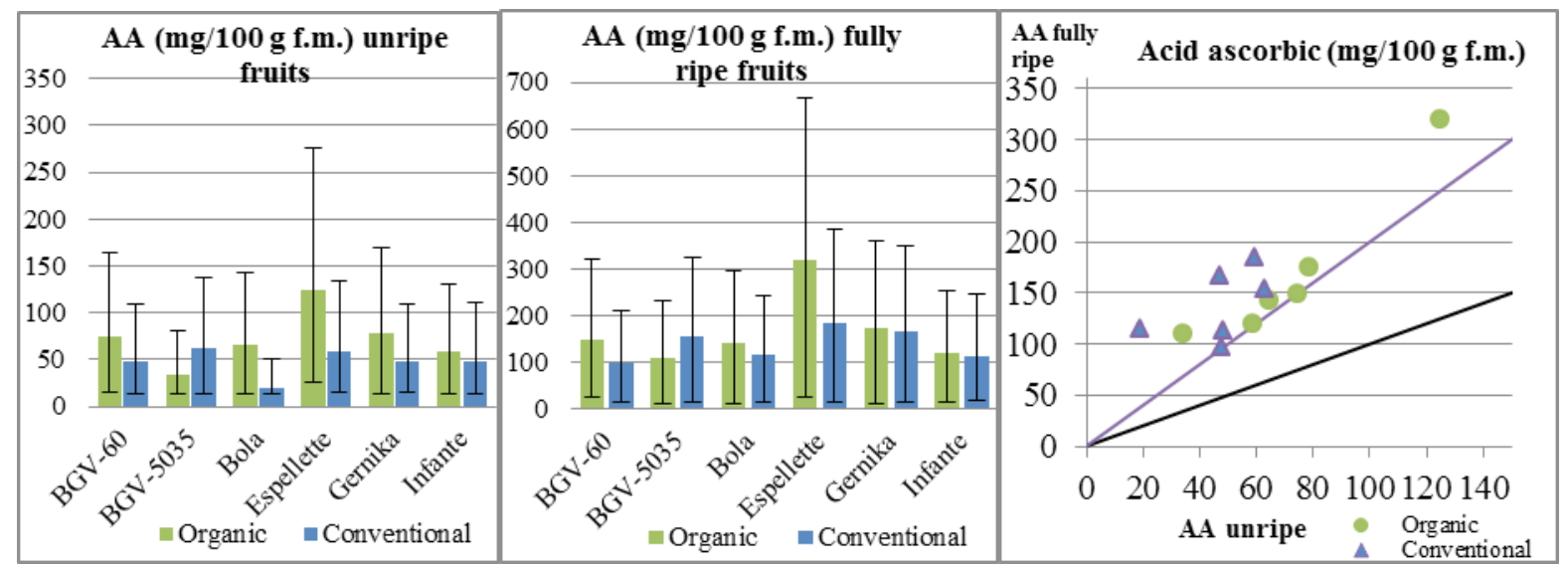

Fig. 1. Average content of ascorbic acid (mg / $100 \mathrm{~g}$ fresh matter) estimated in unripe (a) and fully ripe fruits (b) of different pepper landraces, evaluated under organic and conventional systems; (c) Comparison of AA content in conventional and organic systems. The oblique lines included in the graph represent the gradient 1 (inferior, relative AA fully ripe / AA unripe $=1,0 \%$ increase with ripening) and gradient 2 (upper, AA fully ripe / AA unripe $=2$, increase of $100 \%$ in maturation).

\section{Results and discussion}

Genotype (G), ripening stage (R), growing conditions (GC), GxGC and GxR showed remarkable contributions to the observed variation for $\mathrm{AA}$ content, specially RS (Tab. 1a). In this regard, ripening increased AA in all accessions (Fig. 1c). The specific ANOVA for ripening stage indicated remarkable contributions for the effects, save $\mathrm{G}$ and GxGC in unripe stage (Tab. 1b). Thus, the analysis by maturity stage showed that at both unripe and fully ripe stages, the average AA content was higher in the organic plot. In this way, most organic-produced accessions showed similar or higher values than their conventional repetitions (except BGV-5035, Fig. 1a). Finally, a significant GxGC interaction was found at fully ripe stage, suggesting that accessions with high AA levels may be selected for organic conditions.

\section{Conclusion}

Our results suggest that there are ample opportunities for selecting vitamin C-rich paprika landraces adapted to organic cultivation, in particular for the fully ripe markets.

\section{references}

1. FAO (2015).Consultation statistics. http://www.fao. org/economic/ess/ess-publications/ess-yearbook/faostatistical-yearbook-2011/es/y http://faostat3.fao.org/

2. Rodriguez-Burruezo A, Nuez F (2006). Mejora de la calidad del pimiento. p. 361-391. En: JM Carrillo, MJ Díez, ML Badenes y G Llácer (eds.), Mejora genética de la calidad de las plantas. Universidad Politécnica de Valencia. 